\title{
Avaliação toxicológica e efeito do extrato acetato de etila da fibra de Cocos nucifera L. (Palmae) sobre a resposta inflamatória in vivo
}

\author{
SILVA, L.C.R.; NUNES-PINHEIRO, D.C.S.*; MORAIS, S.M.; LOPES-NETO, B.E.; SANTOS, G.J.L.; CAMPELLO, \\ C.C. \\ Programa de Pós-Graduação em Ciências Veterinárias da Universidade Estadual do Ceará (UECE), Avenida \\ Paranjana, 1700, Campus do Itaperi, Serrinha, CEP:60740-000, Fortaleza-Brasil * csnpdiana@hotmail.com
}

\begin{abstract}
RESUMO: Objetivou-se investigar o efeito do extrato acetato de etila de Cocos nucifera (EAECN) sobre parâmetros fisiológicos e sobre a inflamação tópica induzida por xileno. EAECN foi obtido a partir da água da fibra da casca do coco verde e o teste fitoquímico indicou a presença de taninos condensados, flavononas, flavonóis, flavononóis, xantonas e esteróides. EAECN foi administrado aos camundongos Swiss por via oral em dose única diária de 10, 30, 100 e $250 \mathrm{mg}$ $\mathrm{Kg}^{-1}$ por cinco dias consecutivos para os protocolos de toxicidade e inflamação tópica. No ensaio de toxicidade foram observadas as freqüências cardíacas e respiratórias, a presença de diarréia, analgesia e apatia e realizada a contagem total dos leucócitos do sangue periférico, avaliação macroscópica dos órgãos e peso relativo do rim, fígado, timo e baço. O efeito do EAECN sobre a inflamação tópica foi realizado utilizando-se grupos testes com as diferentes concentrações de EAECN e grupos controles positivos que receberam, pela mesma via nas mesmas condições, $\mathrm{NaCl} 0,9 \%$ ou DMSO a $5 \%$ ou o antiinflamatório padrão, Dexametasona (6 $\left.\mathrm{mg} \mathrm{Kg}^{-1}\right)$. Todos os animais receberam o agente flogístico $(25 \mu \mathrm{L})$ nas partes interna e externa da orelha duas horas após o último tratamento, enquanto os animais do grupo controle negativo não receberam qualquer tratamento. Após 50 minutos da aplicação do xileno, os animais foram sacrificados, e uma porção de cada orelha foi retirada e pesada. A diferença de peso entre as orelhas representa 0 efeito induzido pelos tratamentos. EAECN não desenvolveu toxicidade, não alterou a contagem total de leucócitos, não alterou o peso e nem o peso relativo dos órgãos dos animais tratados em relação aos controles. EAECN não inibiu a inflamação provocada pelo xileno, apresentando efeito pró-inflamatório dependente da dose. Conclui-se que EAECN nos protocolos utilizados não é tóxico e não possui atividade antiinflamatória tópica.
\end{abstract}

Palavras-chave: Cocus nucifera, xileno, Inflamação tópica, toxicidade, parâmetros fisiológicos

\begin{abstract}
Toxicological evaluation and effect of ethyl acetate extract of the fiber of Cocos nucifera L. (Palmae) on inflammatory response in vivo. This study aimed to investigate the effect of ethyl acetate extract of Cocos nucifera (EAECN) on physiological parameters and xylene-induced topic inflammation. EAECN was obtained from the water of the green coconut husk fiber and the phytochemical test indicated the presence of condensed tannins, flavanones, flavonols, xanthones and steroids. EAECN was orally administered to Swiss mice at a single daily dose of $10,30,100$ and $250 \mathrm{mg} \mathrm{Kg}^{-1}$ during five consecutive days for toxicity and topic inflammation protocols. Toxicity experiments included the observation of heart and respiratory frequencies, diarrhea, analgesia and apathy, besides total leukocyte count in peripheral blood, macroscopic evaluation of the organs, and relative weight of kidneys, liver, thymus and spleen. The effect of EAECN on topic inflammation was assessed using test groups with different EAECN concentrations and positive control groups which received, by the same route and conditions, $\mathrm{NaCl} 0.9 \%$, DMSO $5 \%$ or reference drug, Dexamethasone $\left(6 \mathrm{mg} \mathrm{Kg}^{-1}\right)$. All the animals received the phlogistic agent $(25 \mu \mathrm{L})$ in the inner and outer parts of the ears two hours after the last treatment, whereas the negative control group animals did not receive any treatment. At 50 minutes after xylene application, the animals were sacrificed and a portion of each of their ears was removed and weighed. The difference between ear weights represents the effect induced by the
\end{abstract}

Recebido para publicação em 10/11/2008

Aceito para publicação em 25/05/2009

Rev. Bras. PI. Med., Botucatu, v.11, n.4, p.429-434, 2009. 
treatments. EAECN did not develop toxicity, change leukocyte total count, or alter animal weight and organ relative weight in treated animals compared with control groups. EAECN did not inhibit the xylene-induced inflammation, demonstrating dose-dependent pro-inflammatory effect. In conclusion, EAECN used as in these experimental protocols is not toxic and does not have topic anti-inflammatory activity.

Key words: Cocos nucifera, xylene, topic inflammation, toxicity, physiological parameters

\section{INTRODUÇÃO}

Inflamação é um processo que envolve uma série de eventos que podem ser desencadeados por numerosos estímulos, tais como, agentes infecciosos, isquemia, interações antígeno-anticorpo e injúrias químicas, térmicas e mecânicas. A resposta inflamatória ocorre em três fases distintas, mediada por diferentes mecanismos: agudo caracterizado por vasodilatação local e aumento da permeabilidade capilar; fase sub-aguda caracterizada por infiltração de leucócitos e células fagocíticas e fase proliferativa crônica, na qual ocorre degeneração do tecido e fibrose (Rotelli et al., 2003).

A resposta inflamatória, dependendo do agente químico, pode ser desencadeada por diferentes mecanismos, tais como a reação anafilática envolvendo dextrana, a reação inflamatória desenvolvida por carragenina e oxazalona e o processo de inflamação neurogênica envolvendo o xileno quando aplicado topicamente.

O mecanismo bioquímico da inflamação neurogênica provocado pelo xileno desencadeia mecanismos celulares envolvidos na regulação da liberação de substâncias pró-inflamatórias originárias de neurônios sensoriais (Richardson \& Vasko, 2002). Esta inflamação é iniciada pela ação de mediadores, tais como acetilcolina, bradicinina, prostaglandinas, capsaicina etc, provocando liberação direta dos neuropeptídeos, pela excitação dos neurônios, com ativação dos seus receptores, incluindo o VR1, B2 e PARs; promovendo, respectivamente, por influxo de cálcio, ativação da proteína quinase $\mathrm{C}$ ou desinibição do fosfatidil inositol bifosfato $\left(\mathrm{PIP}_{2}\right)$ (Richardson \& Vasko, 2002).

Cocos nucifera, planta típica do nordeste brasileiro, é muito utilizada pela população. A água do fruto é consumida de maneira abundante e o fruto é apreciado para consumo na culinária e indústria alimentícia, enquanto a fibra da casca do coco tem sido utilizada na indústria na confecção de redes, sofás e bancos de carro, entre outros. Muitos estudos foram publicados utilizando a água de coco verde em medicina humana e medicina veterinária.

Nos últimos anos, pesquisadores têm demonstrado interesse em estudar a água da fibra da casca do coco verde ou preparação de extratos a partir da fibra seca da casca do coco. Estudos realizados por Esquenazi et al. (2002) demonstraram que o extrato acetato de etila da fibra da casca de Cocos nucifera apresentava atividades antimicrobiana e antiviral. Estudos fitoquímicos detectaram a presença de catequinas, epicatequinas e taninos como constituintes do mesmo. Mendonça-Filho et al. (2004), utilizando este mesmo extrato, demonstraram a atividade leishmanicida in vitro e sugeriram o efeito imunomodulador sobre os macrófagos ativados.

O objetivo do presente trabalho foi investigar o efeito do extrato acetato de etila de Cocos nucifera (EAECN) sobre parâmetros fisiológicos e sobre a inflamação tópica induzida por xileno, in vivo.

\section{MATERIAL E MÉTODO}

\section{Obtenção do extrato acetato de etila da água da casca de Cocos nucifera}

Resíduos de cocos verdes foram prensados, triturados (Fortalmag, modelo UBRC) para obtenção da água da fibra da casca do coco verde (ACCV) que foi congelada a $-10^{\circ} \mathrm{C}$, a fim de evitar o processo de fermentação. 20 litros de ACCV foram descongelados e filtrados a vácuo. O extrato acetato de etila de Cocos nucifera (EAECN) foi obtido utilizando-se como substância extratora o acetato de etila numa proporção de $20 \%$. Foram recuperados $14 \mathrm{~g}$ de EAECN. O referido extrato foi administrado aos animais solubilizado em DMSO a $5 \%$ em $\mathrm{NaCl} 0,9 \%$, como veículo.

\section{Estudo fitoquímico do extrato acetato de etila de Cocos nucifera (EAECN)}

Testes fitoquímicos do EAECN foram realizados para verificar a presença de heterosídeos cianogênicos, fenóis, taninos, antocianidinas, antocianinas, flavonóides, catequinas, flavanonas, flavonóis, flavanonóis, xantonas, esteróides, triterpenóides, saponinas e alcalóides, de acordo com Matos (1997).

\section{Animais}

Foram utilizados camundongos Swiss, fêmeas, entre 2 e 4 meses, pesando entre 22 e 32 gramas, oriundos de colônias do Biotério Central da Universidade Federal do Ceará. Os animais foram mantidos na sala de experimentação animal do 
Laboratório de Imunologia e Bioquímica (LIBA/FAVET) da Universidade Estadual do Ceará em caixas plásticas sob condições adequadas de luz e temperatura, recebendo ração e água à vontade. Os animais foram manuseados de acordo com as normas éticas da experimentação animal. O protocolo experimental foi aprovado pelo Comitê de Ética para uso de animais (CEUA) da Universidade Estadual do Ceará (Protocolo 08352607-2).

\section{Avaliação dos parâmetros fisiológicos e do aspecto macroscópico dos órgãos linfóides}

Sessenta camundongos Swiss foram divididos em seis grupos $(n=10)$. Os animais receberam $0,2 \mathrm{~mL}$ do EAECN, nas doses de 10, 30, 100 e $250 \mathrm{mg} \mathrm{Kg}^{-1}$ em dose única diária, através de sonda orogástrica, durante cinco dias consecutivos de acordo com o seguinte protocolo: Grupo I - animais que receberam $\mathrm{NaCl}$ 0,9\%, como controle; Grupo II animais que receberam DMSO a $5 \%$ em $\mathrm{NaCl} 0,9 \%$, como veículo; Grupo III - animais que receberam EAECN $10 \mathrm{mg} \mathrm{Kg}^{-1}$; Grupo IV - animais que receberam EAECN $30 \mathrm{mg} \mathrm{Kg}^{-1}$; Grupo V - animais que receberam EAECN $100 \mathrm{mg} \mathrm{Kg}^{-1}$; Grupo VI animais que receberam EAECN $250 \mathrm{mg} \mathrm{Kg}^{-1}$. Os animais foram observados com 1/2, 2, 4, 8, 24, 48 e $72 \mathrm{~h}$ após os tratamentos. O exame clínico destes animais foi baseado na observação das freqüências respiratória e cardíaca; mudanças comportamentais e parâmetros como diarréia, analgesia, contorções, sialorréia, apatia, lacrimejamento, pêlo eriçado, entre outros. No sexto dia, os animais foram pesados, coletadas amostras de sangue; e, em seguida, eutanasiados e necropsiados para observação macroscópica, e retirados o timo, o baço, o rim e o fígado, para serem pesados. Foi calculado o peso relativo dos órgãos. As amostras de sangue foram coletadas do plexo retro-orbital nos dias zero e no sexto dia, com auxílio de pipetas Pasteur e foram acondicionadas em tubos contendo heparina. A contagem total dos leucócitos foi realizada, utilizandose uma câmara de Neubauer.

\section{Efeito do EAECN sobre o processo inflamatório induzido por xileno}

Oitenta camundongos Swiss foram divididos em oito grupos de 10 animais cada, recebendo os tratamentos, durante cinco dias consecutivos, por via oral, através de sonda orogástrica, de acordo com o seguinte protocolo: Grupo I - animais que não receberam tratamento (controle negativo); Grupo II animais que receberam $\mathrm{NaCl} 0,9 \%$; Grupo III - animais que receberam DMSO $5 \%$ em $\mathrm{NaCl} 0,9 \%$, como veículo; Grupo IV - animais que receberam EAECN $10 \mathrm{mg} \mathrm{Kg}^{-1}$; Grupo V - animais que receberam EAECN $30 \mathrm{mg} \mathrm{Kg}{ }^{-1}$; Grupo VI - animais que receberam
EAECN $100 \mathrm{mg} \mathrm{Kg}^{-1}$; Grupo VII - animais que receberam EAECN $250 \mathrm{mg} \mathrm{Kg}^{-1}$; Grupo VIII - animais que receberam dexametasona $6 \mathrm{mg} \mathrm{Kg}^{-1}$, como droga de referência. Após cinco dias dos tratamentos, $2 \mathrm{~h}$ após o último tratamento, os animais receberam 25 $\mu \mathrm{L}$ de xileno nas faces interna e externa da orelha direita, exceto o Grupo I, controle negativo. Após 50 minutos da aplicação do xileno, os animais foram eutanasiados, e foi retirada uma porção de $5 \mathrm{~mm}$ das orelhas direita e esquerda de cada camundongo. As porções foram pesadas e a diferença de peso entre as orelhas representa o efeito provocado pelos tratamentos sobre o processo inflamatório induzido pelo xileno (Kou et al., 2005).

\section{Análise estatística}

Os resultados foram expressos como média \pm d.p. e analisados por ANOVA, seguido dos testes: SNK para análise do peso dos animais e peso relativo dos órgãos; teste de Wilcoxon para análise dos leucócitos totais; teste de Kruskall-Wallis para análise da diferença de peso entre a orelha direita e esquerda. Foi considerado significativo o nível de $5 \%$. Foi utilizado o Programa SAS 1999.

\section{RESULTADO}

\section{Estudo fitoquímico do extrato acetato de etila de Cocos nucifera (EAECN)}

O teste fitoquímico indicou a presença de taninos condensados, flavononas, flavonóis, flavononóis e xantonas. EAECN também apresentou esteróides em baixa concentração.

\section{Efeito do EAECN sobre os parâmetros fisiológicos e sobre os aspectos macroscópicos dos órgãos linfóides}

Os grupos tratados não demonstraram diferença significativa de peso nos dias 0 e 6 do experimento. EAECN nas doses de 10, 30, 100 e $250 \mathrm{mg} \mathrm{Kg}^{-1}$ não provocou toxicidade aparente nos animais e não ocorreu nenhuma morte (Tabela 1). Os animais foram observados diariamente e não demonstraram mudanças comportamentais e nem apresentaram diarréia, apatia, lacrimejamento, sialorréia, emagrecimento e pêlo eriçado.

A contagem dos leucócitos totais dos grupos avaliados foi realizada nos dias 0 e 6 do experimento, demonstrando que não houve diferença significativa dentro do mesmo grupo. No dia 6, os animais foram necropsiados e retirados o fígado, o baço, o timo e o rim, para o cálculo do peso relativo dos órgãos (Tabela 2). Não houve alteração macroscópica dos órgãos e nem houve alteração no peso dos órgãos induzido pelo tratamento. 
TABELA1. Toxicidade aguda de EAECN administrado por via oral.

\begin{tabular}{ccccc}
\hline \multirow{2}{*}{ Tratamentos } & Mortalidade & \multicolumn{2}{c}{ Peso $(\mathrm{g})$} & \multirow{2}{*}{$\begin{array}{c}\text { Sintomas } \\
\text { tóxicos }\end{array}$} \\
\cline { 3 - 4 } & & Dia 0 & Dia 6 & \\
\hline NaCl 0,9\% & $0 / 10$ & $32,02 \pm 1,42^{\mathrm{a}}$ & $31,72 \pm 2,17^{\mathrm{a}}$ & nenhum \\
DMSO 5\% & $0 / 10$ & $22,40 \pm 2,66^{\mathrm{c}}$ & $23,20 \pm 2,56^{\mathrm{c}}$ & nenhum \\
EAECN $10 \mathrm{mg} \mathrm{Kg}^{-1}$ & $0 / 10$ & $25,43 \pm 2,48^{\mathrm{b}}$ & $26,88 \pm 2,58^{\mathrm{b}}$ & nenhum \\
EAECN $30 \mathrm{mg} \mathrm{Kg}^{-1}$ & $0 / 10$ & $29,89 \pm 2,47^{\mathrm{a}}$ & $28,37 \pm 2,11^{\mathrm{a}}$ & nenhum \\
EAECN $100 \mathrm{mg} \mathrm{Kg}^{-1}$ & $0 / 10$ & $23,19 \pm 1,53^{\mathrm{c}}$ & $23,47 \pm 0,79^{\mathrm{c}}$ & nenhum \\
EAECN $250 \mathrm{mg} \mathrm{Kg}^{-1}$ & $0 / 10$ & $30,63 \pm 2,75^{\mathrm{a}}$ & $30,41 \pm 2,23^{\mathrm{a}}$ & nenhum \\
\hline
\end{tabular}

Letras distintas representam diferenças significativas entre tratamentos $(p<0,05)$.

TABELA 2. Leucócitos totais e peso relativo dos órgãos de animais tratados com EAECN.

\begin{tabular}{ccccccc}
\hline \multirow{2}{*}{ Tratamentos } & \multicolumn{3}{c}{ Leucócitos totais $\left(\mathrm{mm}^{3}\right)$} & \multicolumn{3}{c}{ Peso relativo dos órgãos $(\mathrm{g})$} \\
\cline { 2 - 6 } Salina & $5160 \pm 820^{\mathrm{b}}$ & $4085 \pm 1235^{\mathrm{b}}$ & $4,93 \pm 0,51^{\mathrm{b}}$ & $0,36 \pm 0,06^{\mathrm{a}}$ & $0,41 \pm 0,09^{\mathrm{a}}$ & $0,66 \pm 0,05^{\mathrm{a}}$ \\
\cline { 2 - 6 } & Dia 0 & Dia 6 & Fígado & Baço & Timo & Rim \\
EAECN 100 mg Kg & $5525 \pm 389^{\mathrm{ab}}$ & $3390 \pm 1014^{\mathrm{b}}$ & $4,99 \pm 0,60^{\mathrm{b}}$ & $0,42 \pm 0,07^{\mathrm{a}}$ & $0,35 \pm 0,08^{\mathrm{a}}$ & $0,68 \pm 0,08^{\mathrm{a}}$ \\
EAECN 250 mg Kg & $7077 \pm 1660^{\mathrm{a}}$ & $6144 \pm 1993^{\mathrm{a}}$ & $5,51 \pm 0,28^{\mathrm{b}}$ & $0,44 \pm 0,08^{\mathrm{a}}$ & $0,40 \pm 0,04^{\mathrm{a}}$ & $0,56 \pm 0,05^{\mathrm{a}}$ \\
\hline
\end{tabular}

Letras distintas representam diferenças significativas entre tratamentos $(p<0,05)$.

\section{Efeito do EAECN sobre o processo inflamatório induzido por xileno}

A Figura 1 apresenta os dados do tratamento com diferentes doses de EAECN, seguido de exposição ao xileno como agente flogístico. O grupo II que recebeu salina fisiológica $(\mathrm{NaCl} 0,9 \%)$, respondeu ao xileno, demonstrando seu efeito inflamatório; enquanto o grupo I, que não recebeu nenhum tratamento, não apresentou características de processo inflamatório, caracterizando o controle negativo. Os grupos que receberam DMSO a $5 \%$ em salina fisiológica e EAECN nas doses de 10, 30, 100 $\mathrm{mg} \mathrm{Kg}^{-1}$ seguidos do agente flogístico não apresentaram diferenças significativas entre si. EAECN na concentração de $250 \mathrm{mg} \mathrm{Kg}^{-1}$ apresentou efeito estimulatório $(p<0,05)$ quando comparado com as outras doses do referido extrato. O antiinflamatório padrão, Dexametasona, inibiu o efeito inflamatório provocado pelo xileno.

\section{DISCUSSÃO}

No presente estudo, o efeito do extrato acetato de etila de Cocos nucifera (EAECN) administrado por via oral, em diferentes doses, foi investigado em modelos experimentais in vivo, avaliando-se os parâmetros fisiológicos e o processo inflamatório tópico. O teste fitoquímico do EAECN indicou a presença de taninos condensados, flavononas, flavononóis, flavonóis e xantonas. De acordo com Di Carlo et al. (1999), estes constituintes exercem atividade antimicrobiana, antiviral, antiulcerogênica, anti-hepatotóxica, hipolipidêmica, antineoplásica, antialérgica e antiinflamatória.

No estudo do efeito do extrato sobre os parâmetros fisiológicos e aspectos macroscópicos dos órgãos linfóides, não houve mortalidade, nem qualquer sintoma de toxicidade sobre os animais estudados. Quando os tratamentos foram comparados entre os dias 0 e 6 não houve diferença significativa do número de leucócitos totais do sangue circulante dentro do mesmo grupo e nem diferença significativa do peso dos órgãos dentro de um mesmo grupo.

Rev. Bras. PI. Med., Botucatu, v.11, n.4, p.429-434, 2009. 


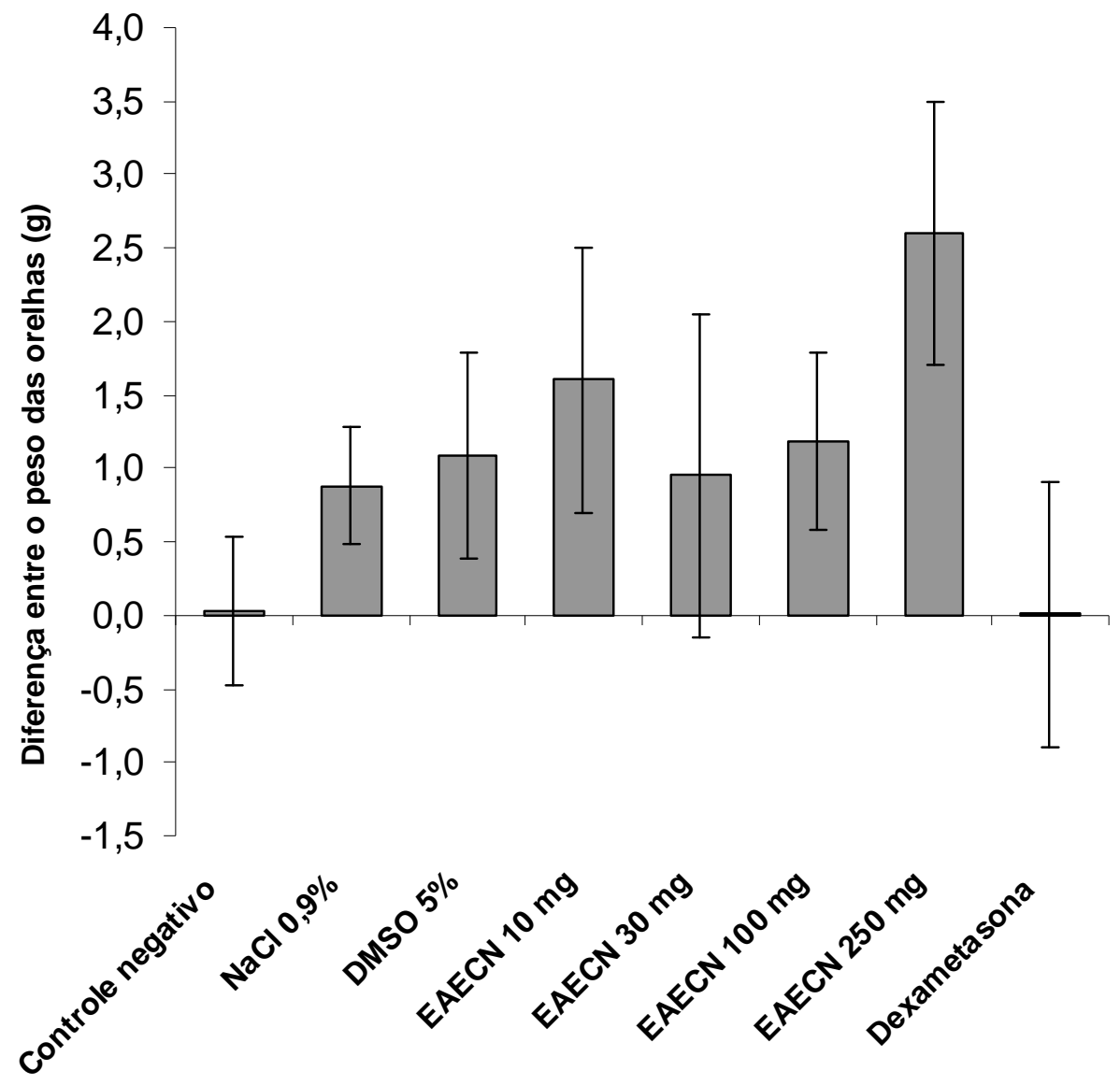

FIGURA 1. Efeito do pré-tratamento com EAECN sobre o edema de orelha induzido por xileno.

Sendo assim, este protocolo revelou-se seguro para sua utilização em outros procedimentos de investigação.

O xileno foi utilizado como agente flogístico por causar irritação na orelha de camundongos, pela promoção de acúmulo de fluídos, característico da resposta inflamatória aguda (Okoli et al., 2007). Neste estudo, verificou-se o efeito sistêmico do EAECN administrado por via oral sobre a inflamação tópica provocada por este agente.

A inflamação provocada pelo xileno induz a liberação de substâncias bioativas liberadas dos terminais periféricos de neurônios sensoriais que agem sobre células alvos periféricas, tais como mastócitos e outras células do sistema imune, produzindo inflamação neurogênica caracterizada por calor, rubor, edema e hipersensibilidade (Richardson \& Vasko, 2002). Neurônios sensoriais são sensíveis à capsaicina, cujo mecanismo está relacionado aos canais vanilóide, sendo responsável pela despolarização e pela liberação direta de neuropeptídeos, como a substância P e o peptídeo relacionado ao gene calcitonina (CGRP), fundamentais nesse tipo de inflamação (Holzer, 1988).

Neste modelo de inflamação tópica, EAECN não apresentou efeito antiinflamatório em nenhuma das concentrações utilizadas em relação aos grupos controles, inclusive EAECN na concentração de $250 \mathrm{mg} \mathrm{Kg}^{-1}$ diferiu significativamente das concentrações mais baixas, demonstrando ser um potente indutor próinflamatório, neste protocolo.

Rotelli et al. (2003), investigando o efeito de flavononas em modelos de inflamação aguda, verificaram que as flavanonas hesperitina e hesperedina inibiram o edema induzido por xileno, em $44 \%$ e $45 \%$, respectivamente. As flavononas presentes no EAECN não inibiram o edema de orelha, demonstrando a ausência das mesmas ou concentrações muito baixas que não são suficientes para induzir o efeito antiinflamatório.

Estudos realizados por Luo et al. (2008) avaliaram a atividade antiinflamatória do extrato de Erigeron multiradiatus (Compositae) e suas frações, tendo a fração butanólica induzido maior redução de edema de orelha provocado por xileno em camundongos, e que estava associado à presença de flavonóides glucuronídeos.

Além disso, o extrato aquoso das folhas de Manihot esculenta Crantz, apresentou efeito antiinflamatório ao reduzir o edema induzido por xileno de forma mais eficiente do que indometacina, a droga 
padrão utilizada. A presença de flavonóides, saponinas e óleos essenciais no extrato justificaram o efeito observado (Adeyemi et al., 2008).

A presença de esteróides e terpenóides no extrato hexânico das folhas de Aspilia africana (Compositae) parecem estar associadas ao potencial antiinflamatório avaliado no modelo de inflamação por xileno (Okoli et al., 2007).

O extrato aquoso de Laggera alata (Asteraceae) também apresentou atividade antiinflamatória no modelo de inflamação tópica induzido por xileno. Estudos fitoquímicos do extrato detectaram a presença de fenóis, dentre eles o ácido dicafeolquínico, que é conhecido por ser um agente antiinflamatório (Wu et al., 2006).

Neste estudo, verificou-se, que apesar de EAECN apresentar várias substâncias com propriedades antiinflamatórias conhecidas, neste modelo experimental o EAECN mostrouse pró-inflamatório na dose mais elevada, contudo as doses inferiores não modificaram o processo inflamatório. As substâncias presentes avaliadas por estudo fitoquímico do $E A E C N$ não inibiram o edema de orelha, demonstrando que a concentração das mesmas ou está muito baixa e não são suficientes para demonstrar efeito antiinflamatório ou apresentam-se estruturalmente diferentes e, portanto, com efeitos biológicos diferentes.

Em conclusão, no modelo de inflamação induzida por xileno, os mediadores liberados neste processo não foram inibidos pelo extrato acetato de etila de Cocos nucifera. Outros protocolos deverão ser utilizados na avaliação do potencial biológico do EAECN.

\section{REFERÊNCIA}

ADEYEMI, O.O.; YEMITAN, O.K.; AFOLABI, L. Inhibition of chemically induced inflammation and pain by orally and topically administered leaf extract of Manihot esculenta Crantz in rodents. Journal of Ethnopharmacology, v.119, p.6-11, 2008.

Di CARLO, G. et al. Flavonoids: old and new aspects of a class of natural therapeutic drugs. Life Sciences, v.65, p.337-53, 1999.

ESQUENAZI, D. et al. Antimicrobial and antiviral activities of poliphenolics from Cocos nucifera LINN. (Palmae) husk fiber extract. Research in Microbiology, v.153, p.64752, 2002.

HOLZER, P. Local effector functions of capsaicinsensitive sensory nerve endings: involvement of tachykinis, calcitonin gene related peptide and other neuropeptides. Neuroscience, v.24, p.739-68, 1988.

$\mathrm{KOU}$, J.P. et al. Anti-inflammatory activities of aqueous extract from Radix Ophiopogon japonicas and its two constituents. Biological and Pharmaceutical Bulletin, v.28, p.1234-8, 2005.

LUO, P. et al. Anti-inflammatory activity of the extracts and fractions from Erigeron multiradiatus through bioassayguided procedures. Journal of Ethnopharmacology, v.119, p.232-7, 2008.

MATOS, F.J.A. Introdução à fitoquímica experimental. 2.ed. Fortaleza: Imprensa universitária, 1997. 139p.

MENDONÇA-FILHO, R.R. et al. Leishmanicidal activity of polyphenolic-rich extract from husk fiber of Cocos nucifera Linn. (Palmae). Research in Microbiology, v.155, p.136-43, 2004.

OKOLI, C.O. et al. Anti-inflammatory activity of hexane leaf extract of Aspilia Africana C.D Adams. Journal of Ethnopharmacology, v.109, p.219-25, 2007.

RICHARDSON, J.D.; VASKO, M.R. Cellular mechanisms of neurogenic inflammation. The Journal of Pharmacology and Experimental Therapeutics, v.302, p.839-45, 2002. ROTELLI, A.E. et al. Comparative study of flavonoids in experimental models of inflammation. Pharmacological Research, v.48, p.601-6, 2003.

WU, Y. et al. Effect of total phenolics from Laggera alata on acute and chronic inflammations models. Journal of Ethnopharmacology, v.108, p.243-50, 2006.

Rev. Bras. PI. Med., Botucatu, v.11, n.4, p.429-434, 2009. 